Research Article

\title{
Determination of Contact Stiffness and Damping of a Tie-Bolt Rotor with Interference Fits Using Model Updating with Thin-Layer Elements
}

\author{
Pu Li iD) ${ }^{1,2}$ and Qi Yuan (iD) 1,2 \\ ${ }^{1}$ School of Energy and Power Engineering, Xi'an Jiaotong University, Xi'an 710049, China \\ ${ }^{2}$ Shaanxi Engineering Laboratory of Turbomachinery and Power Equipment, Xi'an 710049, China \\ Correspondence should be addressed to Pu Li; lipu1215@xjtu.edu.cn
}

Received 5 August 2020; Revised 14 October 2020; Accepted 6 November 2020; Published 19 November 2020

Academic Editor: Athanasios Chasalevris

Copyright (C) $2020 \mathrm{Pu} \mathrm{Li}$ and Qi Yuan. This is an open access article distributed under the Creative Commons Attribution License, which permits unrestricted use, distribution, and reproduction in any medium, provided the original work is properly cited.

Tie-bolt rotors are commonly applied in aeroengines and gas turbines, and interference fits ensure accurate positioning for disk assembling. This paper presents experimental and numerical studies on the stiffness and damping properties of a tie-bolt rotor with interference fits under different preloads. An FE model incorporating thin-layer elements is used to carry out model updating to predict the contact stiffness and damping characteristics. A two-step model updating approach of the tie-bolt rotor using the response surface optimization is implemented. Finally, a quasistatic FE simulation concerning the interference fits and sensitivity analysis is performed to validate the experimental results. Press fit induces a bilinear contact stiffness. Also, modal damping demonstrates a more sensitive and nonmonotonic behavior versus preload.

\section{Introduction}

Tie-bolt rotors are widely used in turbomachinery such as aeroengines and gas turbines. In the framework of aeroengines, the requirement of a high thrust-to-weight ratio renders a more complex structure connected by bolted joint and spline coupling joint $[1,2]$. Concerning gas turbines, two combined rotor profiles can be distinguished: multistage disks are clamped either by a central tie-bolt $[3,4]$ or by several circumferentially distributed rods $[5,6]$. Furthermore, combined rotor with a single central tie-bolt is also applied in centrifugal compressors $[7,8]$.

The advantage of tie-bolt rotors lies in a better stiffness behavior and easy manufacturing. Furthermore, the configuration allows a complex interior profile that is usually indispensable to account for cooling passages in gas turbines. On the other hand, discontinuous connection also introduces interface nonlinearity. Therefore, typical nonlinear behavior, such as resonance shift induced by different excitations [9] and jump phenomena due to bolt loosening [10], causes difficulties for prototyping and health monitoring of combined rotor systems. Detection of bolt loosening is achieved by different methodologies involving experimental modal testing [11], impact modulation [12], and noncontact laser tests [13]. Time-varying stiffness and the corresponding dynamics have been discussed in $[14,15]$. The strength of nonlinearity is determined by the contact status of interface that is influenced not only by the preload of the tie-bolt but also by external forces [16]. Actually, a linear modal analysis can be acceptable if the structural integrity is guaranteed. For instance, dynamics of rod-fastened rotors used in heavy-duty gas turbines are merely influenced by the contact stiffness [5]. However, in the context of jet engine, heavy loads as well as high speed yield a considerable stiffness loss due to joint connection. It is essential to take the stiffness variation under different working conditions into account $[2,17,18]$. Concerning a seven-stage compressor, a disparity of $14 \%$ natural frequency has been reported in [8]. Dynamics of the tie-bolt rotor incorporating nonlinear contact stiffness have been discussed in $[18,19]$. 
Stiffness and damping are two main parameters for dynamic analysis of the jointed structure. Concerning the nonlinear phenomenon, a detailed review of existing models for simulation has been presented in [20-22]. As stated in [22], the dynamical behavior can be described by existing models quite well and the efficiency has become a concern for industry applications. Zero-length elements and thin-layer elements have been commonly used to consider the influence of the contact interface in the dynamic analysis. Applying the zero-length elements, coupling interfaces are connected by a user-defined constitutive model such as spring-damper element $[23,24]$. The contact properties are either calculated by analytical models $[25,26]$ or determined by modal experiments $[27,28]$. In contrast, thin-layer element was firstly used in the soil-structure interaction in the 1980s [29]. It is quite convenient to account for the contact effects in commercial FE software. Elasticity of the thin-layer elements is adjusted to consider the variation of contact stiffness versus pretension of bolts. Damping of the contact interface is a key factor that reflects the energy dissipation of the jointed structure. With the well-developed model, the contact stiffness can be well predicted while the prediction of damping is challenging, especially when macroslip occurs between the coupling interfaces. Furthermore, experimental tests are usually applied to obtain modal parameters for model updating [28, 30-32].

The prediction of contact stiffness and damping of jointed structures have been widely studied [21]. However, most investigations are based on simple beam connections. Tie-bolt rotor that is composed of several disks clamped by multiple tie-bolts, usually demonstrates a more complex behavior. Furthermore, the influence of interference fits on the contact status as well as on the corresponding modal parameters has not been studied thoroughly.

In this paper, the influences of bolt preload on the modal parameters will be investigated by performing an experimental modal test. An FE model incorporating thin-layer elements will be used to consider the contact effects in modal analysis. Interface stiffness and damping will be determined by a two-step model updating approach. Furthermore, sensitivity analysis is provided to better understand the modal behavior. The manuscript is organized as follows: Section 1 describes the experimental tie-bolt rotor with different preloads. Section 2 presents the procedure of the modal test. Section 3 collects the experimental results while Section 4 offers a further discussion. Finally, Section 5 concludes the paper.

\section{Experimental Modal Testing}

2.1. Tie-Bolt Rotor Description. Figure 1 depicts the cross section of the tie-bolt rotor with distributed connections of tie-bolts. The rotor is composed of 2 shafts, 2 disks, and 3 connecting segments (see the green parts). The rotor components are clamped by four groups of circumferentially distributed bolts. M16 bolts connect the shafts and the connecting segments while M20 bolts connect the disks and the connecting segments. There exist 6 contact pairs tightened by tie-bolts. Furthermore, press fits between 6 circular surfaces assure radial position of rotor disks.

For the preload controlling approach, it is necessary to determine the contact pressure and status information at the interface. Because there are 30 tie-bolts under pretension, it is more convenient to use disk springs to get the axially preload with the help of force-deformation relationship as depicted in Appendix A. Therefore, in order to get the modal parameters with a varying preload, different torques are applied at two types of tie-bolts, i.e., M16 and M20.

2.2. Experimental Modal Testing. A free-free boundary impact testing is performed to investigate the influence of preload on natural frequency and modal damping. Seven PCB accelerometers (sensitivity: $10.22-10.38 \mathrm{mV} / \mathrm{ms}^{-2}$ ) are located at 7 axial positions. The rotor is suspended by an elastic cable at two locations, see Figure 2. Hence, the mode shape can be obtained directly by a single modal test.

The rotor is tightened by two groups of tie-bolt, i.e., M16 and M20, respectively. To study the influence of axially distributed preload on modal parameters, experimental modal testing with two sequentially varying pretensions is carried out as shown in Table 1. Firstly, an experimental test is performed by changing the torque at the M16 bolt from 10 to $90 \mathrm{Nm}$ while the torque at the M20 bolt is kept constant at $110 \mathrm{Nm}$. The corresponding nominal pressure at contact interface 1 and 6 varies from 3.17 to $7.81 \mathrm{MPa}$ while the nominal pressure at contact interface $2-5$ is $7.48 \mathrm{MPa}$. Then, the modal response is obtained by altering the torque at M20 from 10 to $110 \mathrm{Nm}$ with a constant torque of $90 \mathrm{Nm}$ at M16 bolt in Case 2. Consequently, the nominal pressure at contact interface 2-5 is increased from 3.17 to $7.81 \mathrm{MPa}$ with the nominal pressure of $7.48 \mathrm{MPa}$ at the contact interface 1 and 6.

Concerning the data acquisition system, a resolution of $0.32 \mathrm{~Hz}$ with the frequency range from 0 to $2560 \mathrm{~Hz}$ has been used. A roving hammer impact test has been carried out five times for one preload case to obtain modal results. Frequency response functions (FRFs) that measure the system's output in response to a known input signal have been obtained as shown in Figure 3. The peaks denote five lateral natural frequencies. The corresponding mode shape is collected in Figure 4 that displays five lateral mode shapes clearly. We observe that the symmetry of the modes is not well presented (e.g., the response at accelerometer no. 2) that might be caused by the connection status of accelerometers. In order to obtain the corresponding modal parameter (frequency and modal damping), an experimental modal analysis is carried out. Natural frequency and modal damping ratio are obtained using the PolyMAX frequencydomain method in LMS TestLab [33].

In Case 1, natural frequency and modal damping ratio of five bending modes versus preload, varying from $10 \mathrm{Nm}$ to $90 \mathrm{Nm}$ on M16 bolts, are collected in Figures 5 and 6. There is only a minor rise in natural frequency of less than $2.2 \%$. Compared to natural frequency, modal damping ratio is more sensitive to the change of preload, see Figure 6. Also, the overall trend of the damping ratio of less than $0.5 \%$ is 


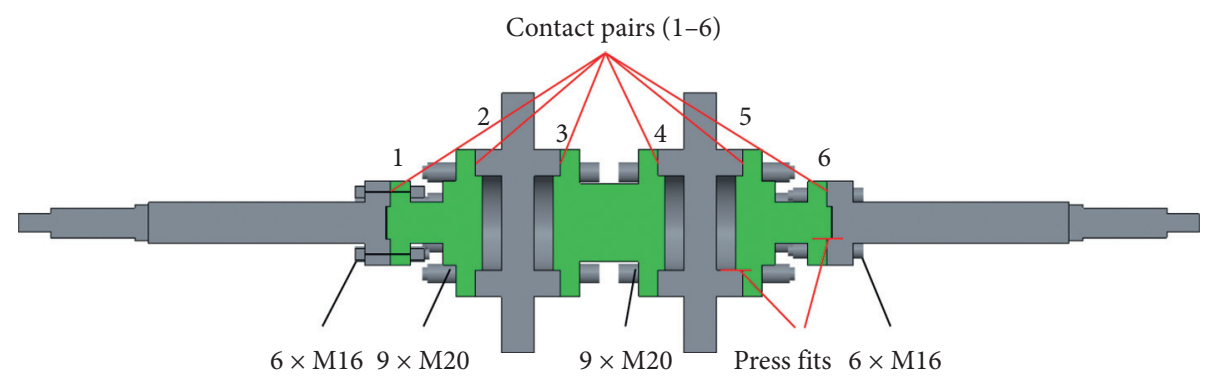

FIGURE 1: Experimental tie-bolt rotor with distributed pretension by tie-bolts.

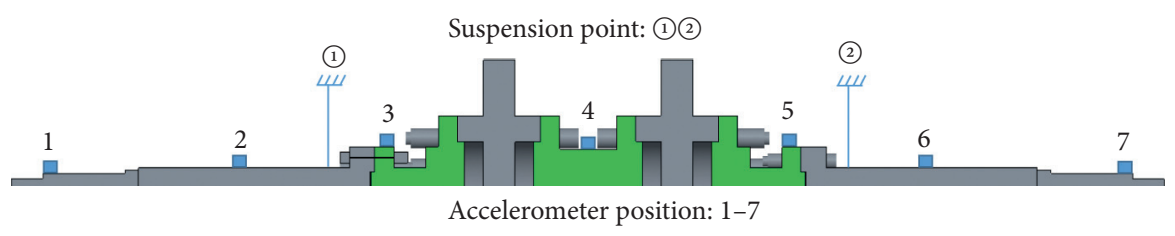

FIGURE 2: Arrangement of accelerometer and suspension locations for the tie-bolt rotor.

TABLE 1: Experimental modal testing with different preloads.

\begin{tabular}{lcc}
\hline Modal tests & Torque $(\mathrm{Nm})(\mathrm{M} 16)$ & Torque $(\mathrm{Nm})(\mathrm{M} 20)$ \\
\hline Case 1 & $10-90$ & 110 \\
\hline Case 2 & 90 & $10-110$ \\
\hline
\end{tabular}

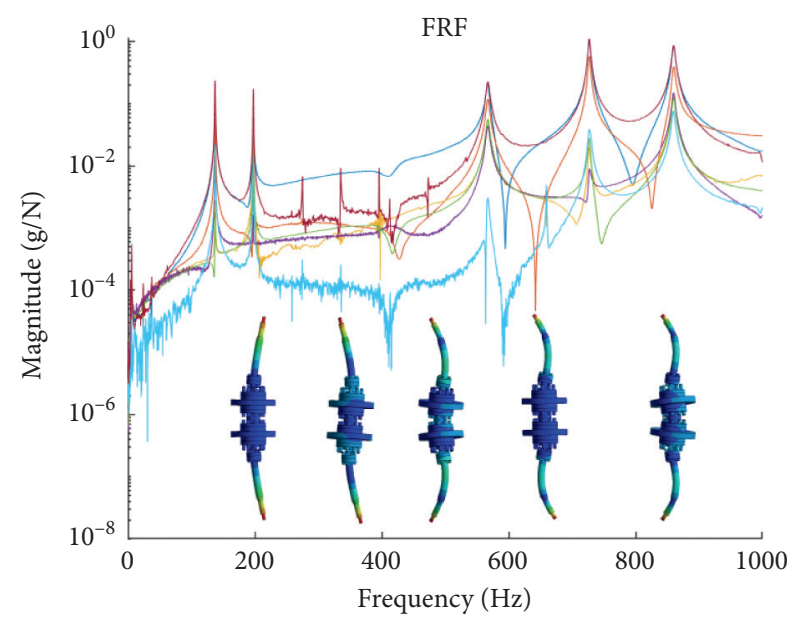

FIGURE 3: Frequency response function (FRF) obtained from seven accelerometers.

decreasing versus a growing preload. However, a nonmonotonic behavior with a peak at the preload of $50 \mathrm{Nm}$ can be witnessed. It may be induced by a bilinear behavior in contact status due to interference fits. A further discussion is presented in Section 4.1.

By contrast, in Case 2, we keep the torque on M16 bolts as constant and change the torque on M20 bolts from $10 \mathrm{Nm}$ to $110 \mathrm{Nm}$. The natural frequencies under free-free boundary conditions versus preload are collected in Figure 7. Similarly, a general growing trend is expected. Moreover, mode 3 and mode 5, with an increase of $9.0 \%$ and $5.4 \%$ over the preload, are more sensitive to the preload than other modes. More details can be found in a sensitivity analysis in Section 4.2. As shown in Figure 8, the modal

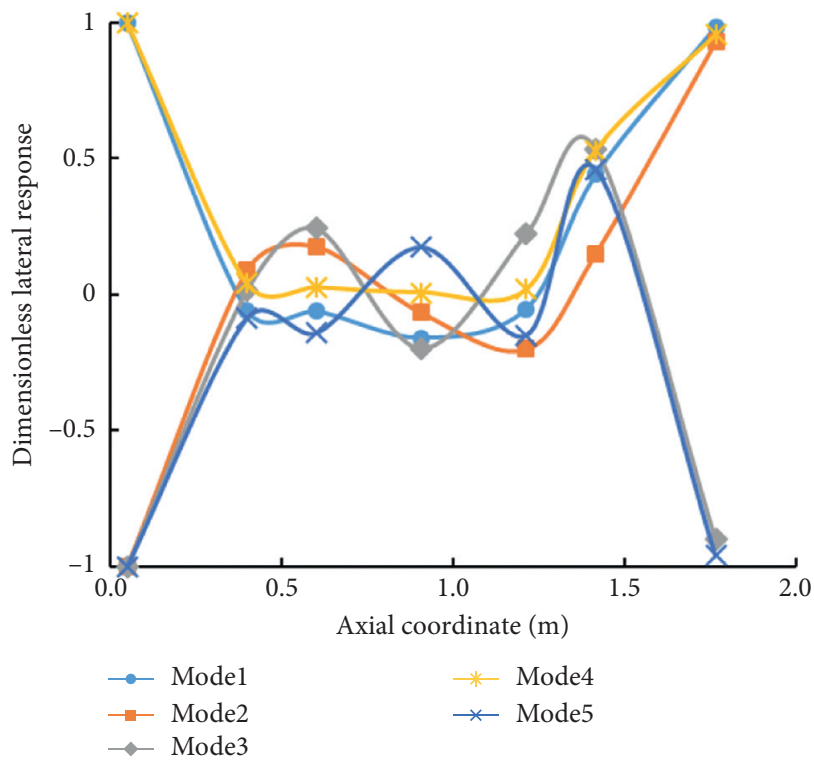

Figure 4: Experimental mode shape of the tie-bolt rotor.

damping ratio is decreasing with a growing preload. For mode 3 and mode 5, we witness a nonmonotonic behavior of the modal damping with increasing torque that is explained in Section 4.2. Compared to Case 1, the influence of pretension on the modal parameters is better demonstrated in Case 2 that will be used for model updating in the following part. Furthermore, it can be observed that modal damping demonstrates a more sensitive behavior than natural frequency, especially for Case 1.

\section{Model Updating Analysis}

Model updating aims at obtaining an accurate FE model to predict the dynamic behavior that agrees with the experimental modal testing. To make it concise, modal parameter 


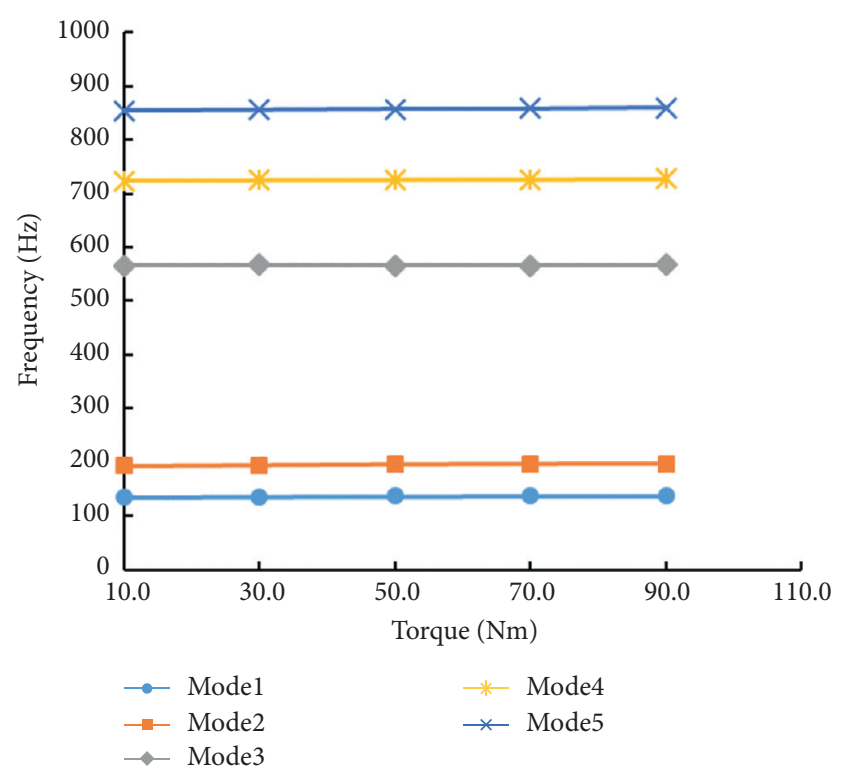

Figure 5: Modal testing results of Case 1: modal frequency versus preload on M16 bolt.

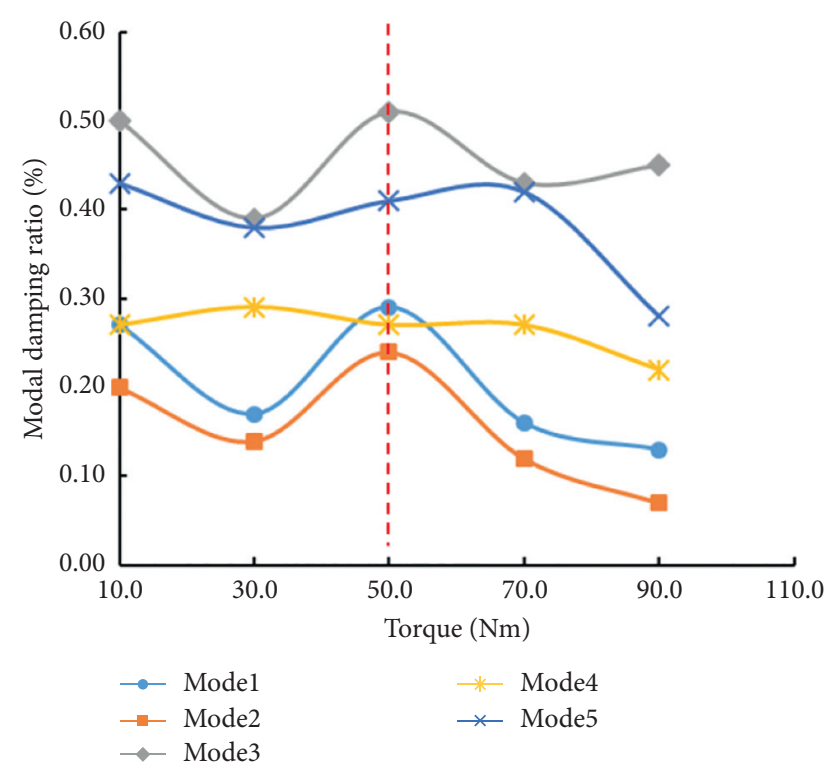

Figure 6: Modal testing results of Case 1: modal damping ratio versus preload on M16 bolt.

estimations are performed according to the modal testing results of Case 2. Thin-layer elements are introduced between contact interfaces $2-5$, and as a result, material properties of the thin-layer elements are updated to take the influence of preloads into account. The 3D FE model incorporating thin-layer elements is shown in Figure 9. In the modal analysis, the nonlinear characteristics will be ignored. All contact interfaces are bonded in the simulation. To denote the influence of preloads of tie-bolt, elasticity of the thin-layer interfaces, as shown in the zoom plot, is altered according to modal experiment.

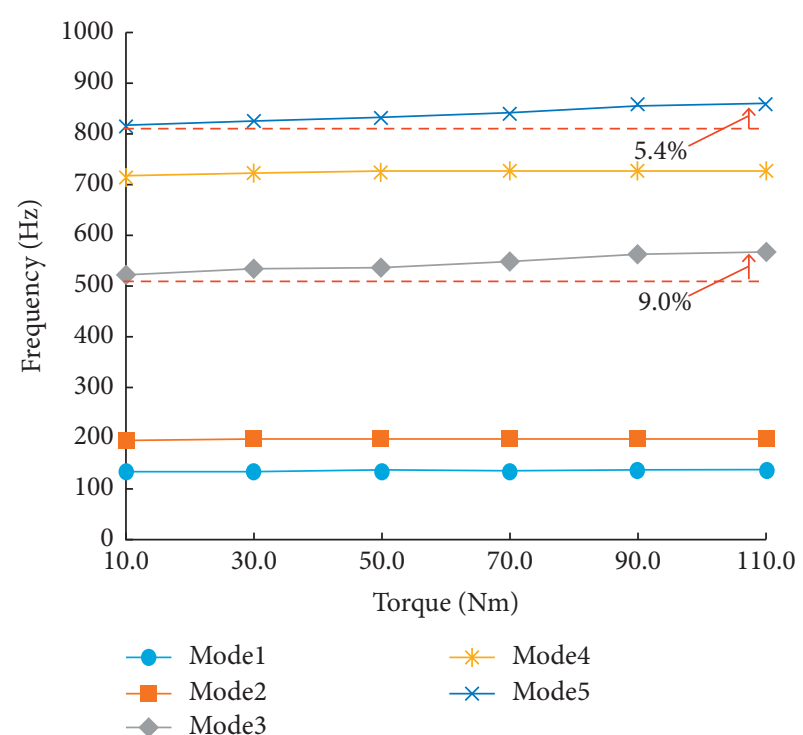

Figure 7: Modal testing results of Case 2: natural frequency versus preload on M20 bolt.

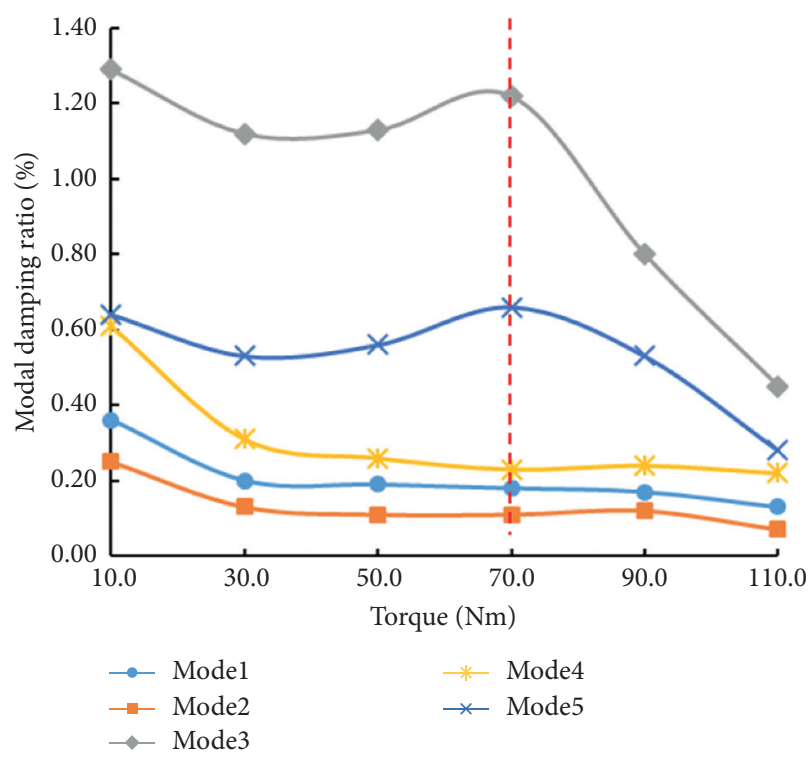

Figure 8: Modal testing results of Case 2: modal damping ratio versus preload on M20 bolt.

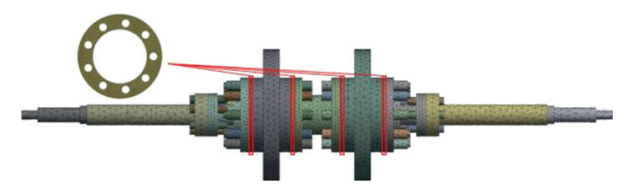

FIGURE 9: FE model with thin-layer element for model updating analysis.

To improve the efficiency of model updating and to distinguish between the influence of contact stiffness and contact damping, a two-step modal updating strategy is applied as shown in the flowchart, see Figure 10. In Step 1, the contact stiffness is updated by performing an undamped 


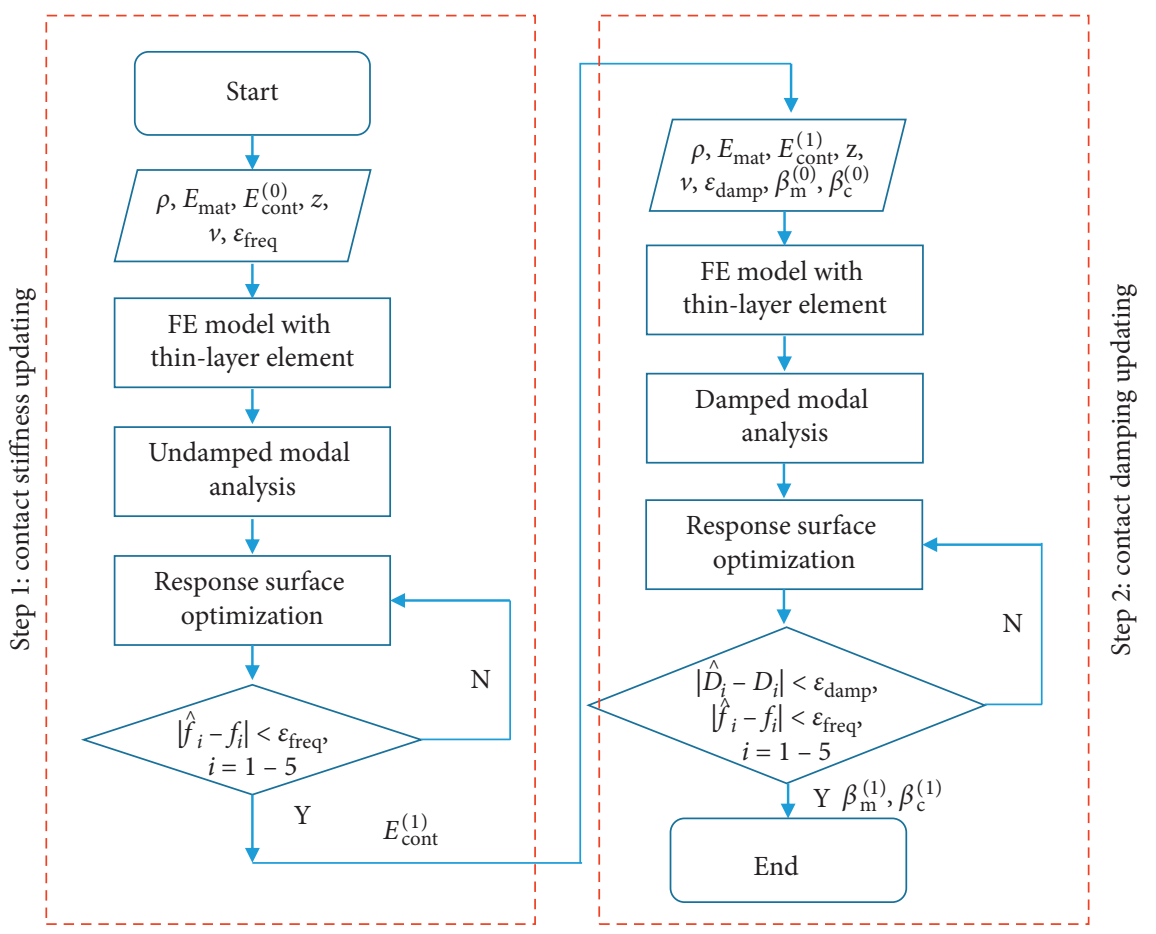

Figure 10: Flowchart of a two-step model updating approach.

modal analysis. The material properties of the FE model are defined in Table 2. Thin-layer element is assumed to be isotropic, and therefore, elasticity of four contact interfaces $E_{\text {cont }}$ is chosen as the parameter for updating. Several undamped modal analyses are performed, and five natural frequencies are selected as output. Then, a response surface can be developed and the multiobjective genetic algorithm (MOGA) is used to find the optimized elasticity under multiple objectives (modal frequency from testing as target $f_{i}, i=1-5$ ) as well as multiple constraints (error bound for every frequency $\left.\varepsilon_{\text {freq }}=2 \%\right)$. For a clear comparison, the optimization is conducted using three different FE models with the thickness of thin-layer element $z=0.1 \mathrm{~mm}, 0.5 \mathrm{~mm}$, and $1 \mathrm{~mm}$. Consequently, the optimized contact stiffness $k_{n}$ is given by

$$
k_{n}=\frac{E_{\mathrm{cont}}}{z}
$$

Figure 11 collects the optimized contact stiffness for the thin-layer element of three different thicknesses. A bilinear stiffness behavior can be seen from the curve with the torque of $70 \mathrm{Nm}$ as the turning point. The bilinear stiffness behavior is due to the change of the contact status that is further discussed in Section 4. The stiffness variation for three models agrees well. The optimized contact stiffness versus preload has been validated by conducting the undamped modal analysis, and Figure 12 summarizes the error of five mode shapes using the thin-layer element with the thickness $z=1 \mathrm{~mm}$

Concerning the thin-layer element, the thickness of $1 \mathrm{~mm}$ is applied for the updating of contact damping. To denote the damping property in the FE model of the tie-bolt
TABLE 2: Material property of the tie-bolt rotor.

\begin{tabular}{lcc}
\hline Density $\rho\left(\mathrm{kg} \cdot \mathrm{m}^{-3}\right)$ & Elasticity $E_{\text {mat }}(\mathrm{Pa})$ & Poisson's ratio $v$ \\
\hline 7850 & $2.06 \times 10^{11}$ & 0.3 \\
\hline
\end{tabular}

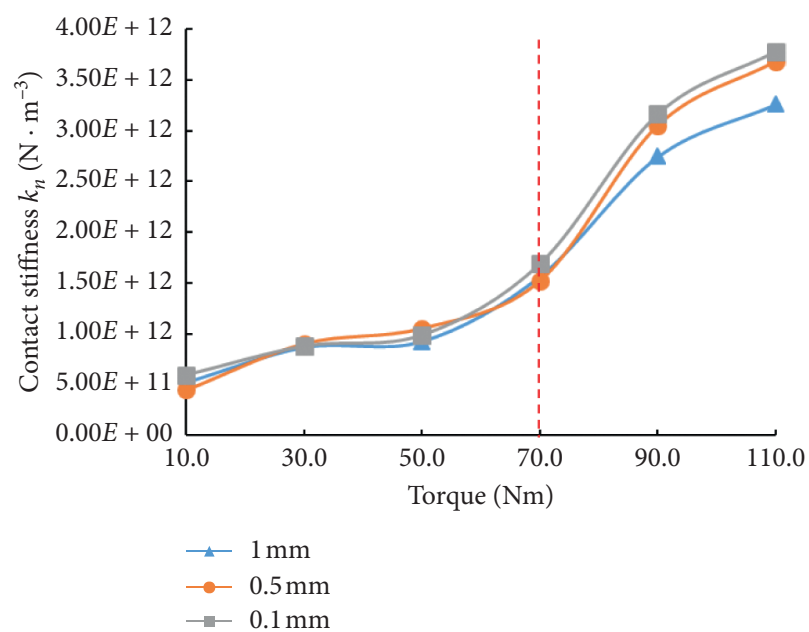

FIgURE 11: Updated stiffness using thin-layer element of three different thicknesses.

rotor, it is possible to consider the influence by introducing two parameters: material damping coefficient and joint damping coefficient that belongs to the stiffness proportional damping. In the framework of Raleigh damping, the mass proportional damping is set as zero. Therefore, the damping can be incorporated in the model by the definition of the complex stiffness matrix as 


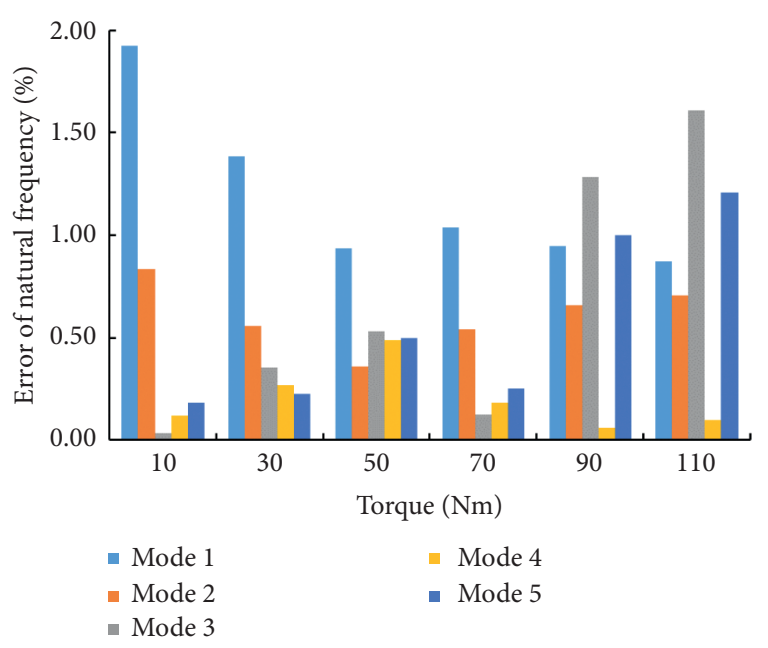

FIGURE 12: Error of natural frequency for five mode shapes using $1 \mathrm{~mm}$ thin-layer element.

$$
K^{*}=K+i \sum_{m} \beta_{m} K_{m}+i \sum_{c} \beta_{c} K_{c}
$$

Therefore, two coefficients are selected as input for the optimization according to the experiment results. The response surface optimization is carried out using MOGA. Based on the updated contact stiffness in the first step, ten constraint conditions including 5 frequencies (error $\varepsilon_{\text {freq }}<2 \%$ ) and 5 modal damping ratios (error $\varepsilon_{\text {damp }}<100 \%$ ) are used for the optimization. It should be mentioned that updating of modal damping represents a process of trial and error that is far more difficult than updating of frequency. Using two proportional coefficients with a stricter error tolerance yields no results. On the other hand, it is possible to tune the damping ratio with a lower error by introducing more control parameters. However, the tendency under different preloads is lost with a higher computational cost. Therefore, only two parameters with the modal damping error of $100 \%$ are used. Two proportional coefficients, i.e., the factor of the rotor without contact parts $\beta_{m}$ and the factor of the thin-layer element $\beta_{c}$, are introduced. The optimized modal damping factors are collected in Figure 13. Generally, the coefficient $\beta_{c}$ demonstrates a decreasing trend versus preload that is more than ten times as the coefficient $\beta_{m}$. It is easy to understand since the joint damping is usually 10-100 times as the material damping [34]. As expected at the turning point of the bilinear stiffness, i.e., the torque of $70 \mathrm{Nm}$, the stiffness factor, i.e., $\beta_{m}$ and $\beta_{c}$, shows a different behavior. Concerning the error of the modal analysis in Figure 14, the higher frequency at mode 4 and 5 shows a larger magnitude since higher frequency response will be overdamped if only stiffness proportional damping is used. The convergence plot of modal damping at the torque of $50 \mathrm{Nm}$ is shown in Figure 15. Therefore, three optimized parameters, denoting the contact stiffness and damping, are obtained using a two-step model updating approach that agrees well with the modal testing results. The advantage of the two-step updating methodology is a clear classification of the influence of modal parameters. Furthermore, it entails a

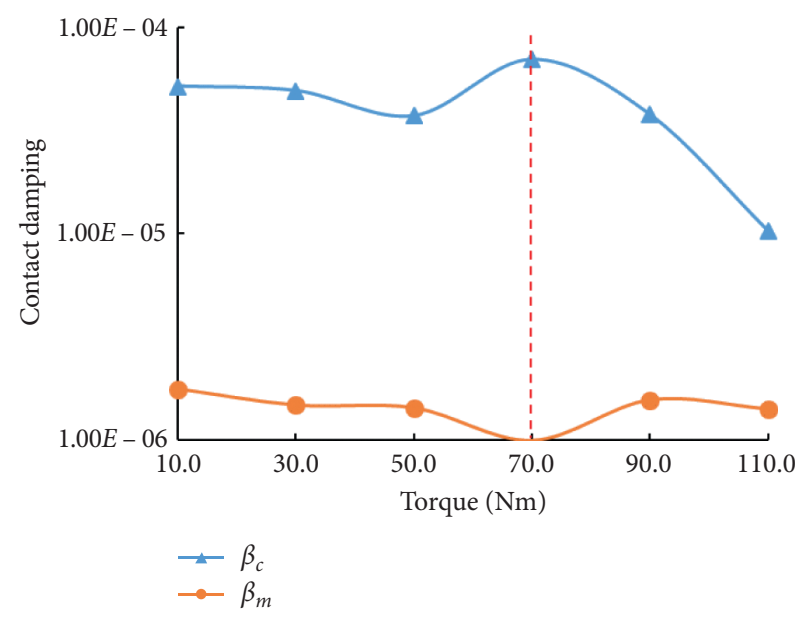

FIGURE 13: Updated modal damping versus preload using $1 \mathrm{~mm}$ thin-layer element.

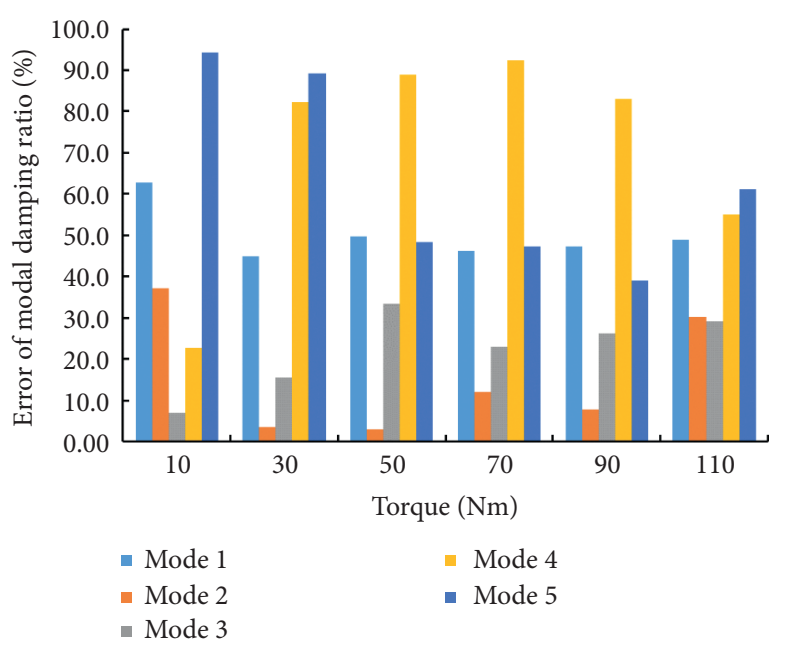

FIgURE 14: Error of modal damping ratio for five mode shapes using $1 \mathrm{~mm}$ thin-layer element.

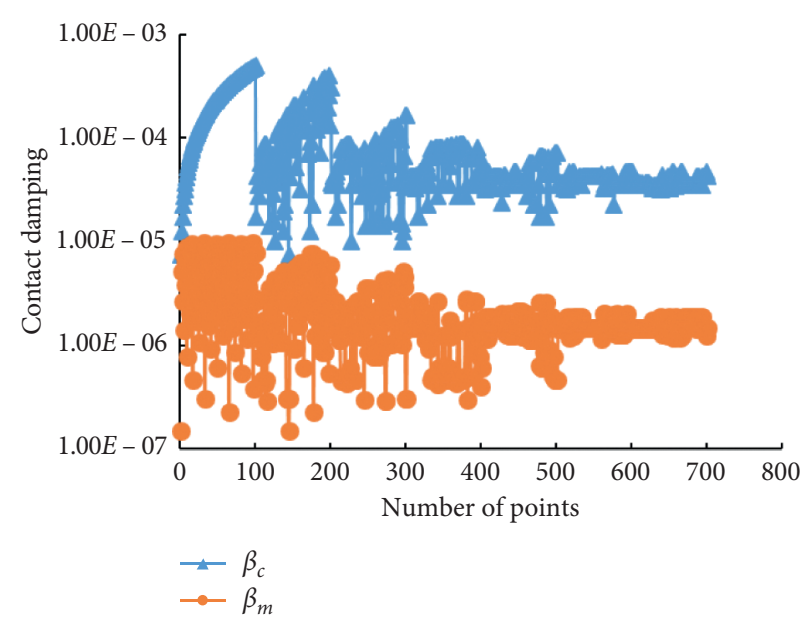

FIGURE 15: Convergence of model parameters under the torque of $50 \mathrm{Nm}$. 
better convergence behavior because a global optimization using three input parameters is likely to suffer from numerical problems with no results.

\section{Discussion}

Experimental modal testing and model updating has been presented above. One interesting phenomenon concerning contact stiffness and damping is the turning point at a specific preload that is due to the interference fits. To explain the results, a nonlinear quasistatic FE simulation is applied in Section 4.1. Another topic to be discussed is the sensitivity of the mode shape with respect to preload. As displayed in Figure 7 , mode 3 and mode 5 are more sensitive to the preload than other modes. Section 4.2 will give a detailed explanation.

4.1. Influence of the Interference Fit. The tie-bolt rotor with a press fit of $0.04 \%$ contact overlap is analyzed by a multistep quasistatic simulation. To this end, the nonlinear contact pairs are firstly defined and then followed by a subsequent multipreloads on the bolts. To model the effects of an interference fit, an offset of the contact surface is defined. The nonlinear contact pair is developed with the frictional coefficient of 0.15 . The resulting stress of the interface connected by M16 and M20 bolts is displayed in Figure 16. Then, a pretension is applied on the multiple bolts according to the torque-pretension curve displayed in Figure 17 in Appendix A. The maximal equivalent stress of the contact interface is collected in Figure 18. It can be observed that there is a sharper increase for the M16 and M20 bolts when the torque on the bolt reaches $50 \mathrm{Nm}$ and $70 \mathrm{Nm}$, respectively. Therefore, the quasistatic contact simulation denotes an explanation for the bilinear stiffness behavior as well as the abrupt turning point of modal damping.

4.2. Sensitivity Analysis of the Mode Shape. Another issue needs to be clarified is that mode 3 and 5 entail a higher sensitivity to preload than other modes concerning modal parameters as shown in Figure 7. The eigenvalue of the FE model concerning the flexural stiffness of the joint can be defined by [35]

$$
\frac{\partial \lambda}{\partial K_{n}^{c}}=\phi_{j}^{T}\left[\frac{\partial K}{\partial K_{n}^{c}}-\lambda \frac{\partial M}{\partial K_{n}^{c}}\right] \phi_{j}=\left(\varphi_{j, n}^{R}-\varphi_{j, n}^{L}\right)^{2} \approx \theta_{n}^{2} .
$$

Therefore, we obtain the sensitivity of the contact pair fastened by M20 bolt that is collected in Table 3. As a result, we can see a clear disparity between the five bending modes. The sensitivity of the third and fifth eigenfrequency with respect to the stiffness of the contact is larger than other three modes.

\section{Conclusions}

In this paper, the contact stiffness and damping properties of a tie-bolt rotor have been studied. Experimental modal analysis is performed with varying pretension of tie-bolts.
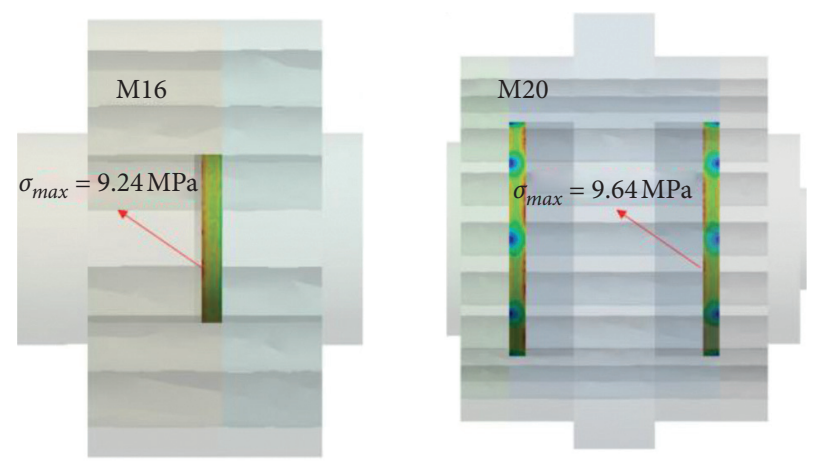

FIGURE 16: Equivalent stress distribution of the contact surfaces with interference fits.

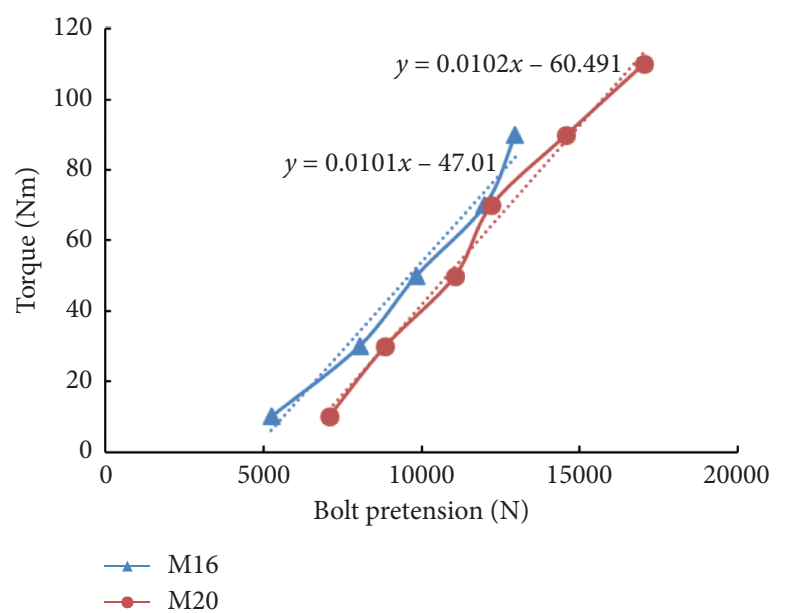

FIGURE 17: Torque-pretension curve according to the properties of disk springs.

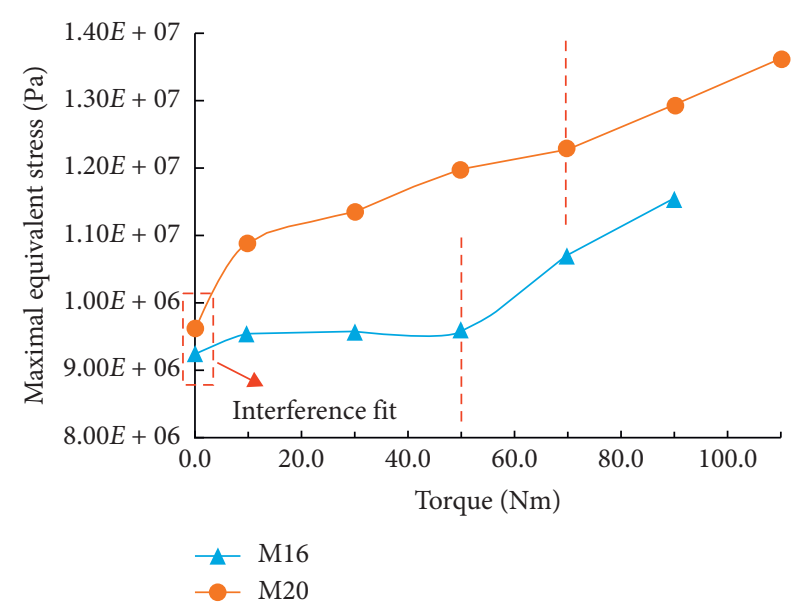

FIGURE 18: Maximal equivalent stress considering the interference fits and the preload.

TABLE 3: Sensitivity of the natural frequency with respect to the contact stiffness for modes 1-5.

\begin{tabular}{lccccc}
\hline Mode & 1 & 2 & 3 & 4 & 5 \\
\hline$\theta_{n}^{2}$ & $6.71 \times 10^{-3}$ & $2.36 \times 10^{-1}$ & $5.44 \times 10^{-1}$ & $6.94 \times 10^{-2}$ & 1.09 \\
\hline
\end{tabular}




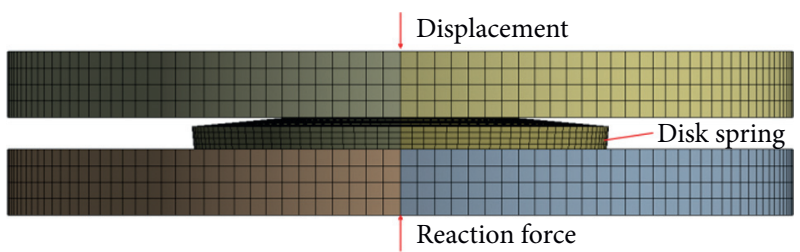

FIGURE 19: FE model to calculate the force-deformation relationship of disk springs.

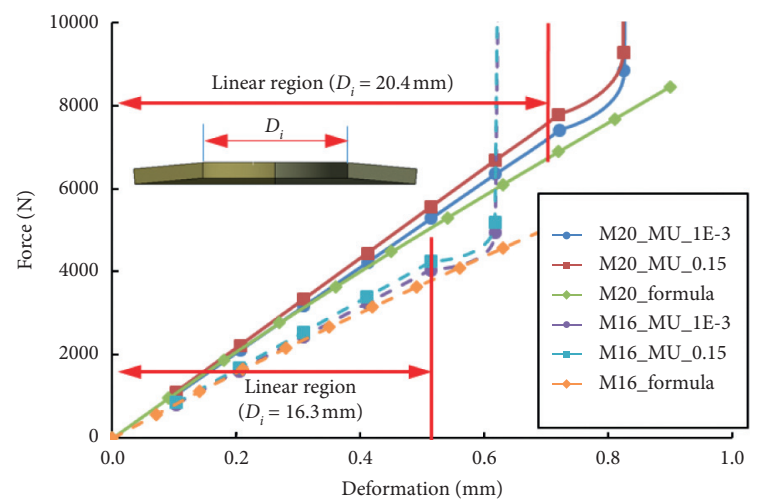

FIgURE 20: A comparative study of the force-deformation relationship of disk springs: FE simulation and the formula of DIN2093.

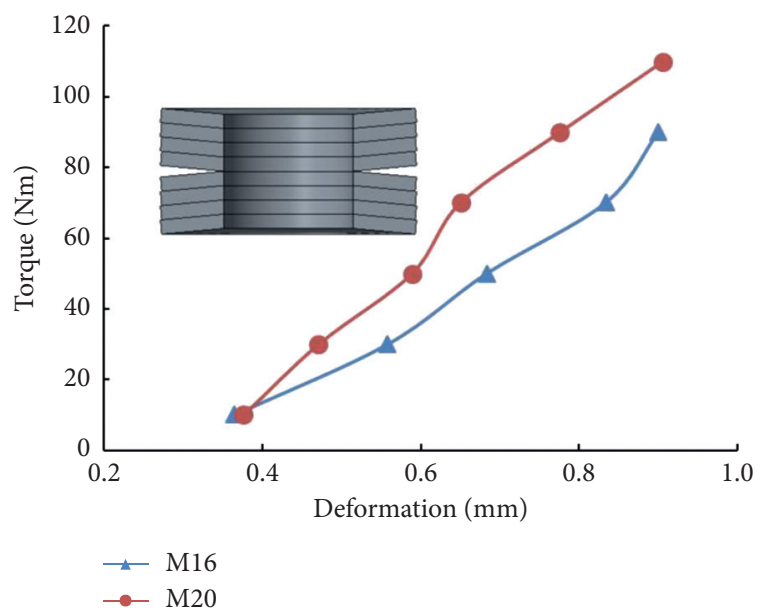

FIgURE 21: Torque-deformation curve of a combination of 8 disk springs.

TABle 4: Parameter of tie-bolt M20 and M16 to determine the torque-pretension relationship.

\begin{tabular}{ccccccc}
\hline & $P(\mathrm{~mm})$ & $d_{2}(\mathrm{~mm})$ & $\mu_{T}$ & $\mu_{H}$ & $D_{f}(\mathrm{~mm})$ & $\alpha(\mathrm{m})$ \\
\hline M20 & 2 & 20 & 0.6 & 0.6 & 26 & 0.015 \\
\hline M16 & 1.5 & 16 & 0.6 & 0.6 & 20.8 & 0.012 \\
\hline
\end{tabular}

Based on the experimental results, the contact stiffness and damping are determined by model updating. Main conclusions can be summarized as follows.

The stiffness and damping properties of the tie-bolt rotor are varied according to the applied torque. With an increasing pretension, natural frequency is increased while the overall damping ratio is reduced. Modal damping is more sensitive to the natural frequency with respect to different preloads.

Thin-layer elements are used to update the FE model according to the experimental results. A two-step updating approach renders a clear distinction between the influence of contact stiffness and damping. Natural frequency can be tuned quite well by updating the elasticity of contact interfaces while the updated Rayleigh damping, i.e., the proportional factor with respect to the stiffness of the rotor $\beta_{m}$ as well as the stiffness of the contact interface $\beta_{c}$, can be accomplished with a relatively larger error of $100 \%$.

The influence of interference fits on the modal parameters is demonstrated experimentally and is further validated by a quasistatic numerical simulation. The interference fit yields a bilinear stress distribution within the contact pairs and subsequently results in a bilinear contact stiffness. Concerning modal damping ratio, the interference fit induces a nonmonotonic behavior with a turning point at a specific preload. The abrupt change in modal damping may be useful for the detection of the contact status with press fits.

Mode 3 and mode 5 are more sensitive to the pretension of the M20 bolts that is justified by a sensitivity evaluation.

\section{Nomenclature}

$D_{i}: \quad$ Inner diameter of disk springs $(\mathrm{m})$

$\beta_{m}$ : Stiffness proportional damping coefficient of the rotor

$\beta_{c}$ : $\quad$ Stiffness proportional damping coefficient of the thin-layer element

$K_{m}: \quad$ Stiffness matrix of the rotor

$K_{c}: \quad$ Stiffness matrix of the thin-layer element

$K^{*}$ : $\quad$ Complex stiffness matrix of the tie-bolt rotor

$\lambda: \quad$ Eigenvalue of the tie-bolt rotor

$K_{n}^{c}$ : $\quad$ Stiffness matrix of an individual contact part

$\phi_{j}: \quad j^{\text {th }}$ eigenvector of the whole rotor $(j=1-5)$

$K: \quad$ Stiffness matrix of the tie-bolt rotor

$M$ : $\quad$ Mass matrix of the tie-bolt rotor

$\varphi_{j, n}^{L}, \varphi_{j, n}^{R}$ : Components of $j^{\text {th }}$ eigenvector on the left and right nodes of the thin-layer element

$\theta_{n}: \quad$ Rotational angle of the thin-layer element

$P: \quad$ Pitch of the tie-bolt $(\mathrm{m})$

$d_{2}: \quad$ Nominal bolt diameter $(\mathrm{m})$

$D_{f}$ : $\quad$ Average of the bolt cap and shaft diameter $(\mathrm{m})$

$\mu_{T}$ : Thread friction coefficient

$\mu_{H}$ : $\quad$ Bolt head friction coefficient 


$\begin{array}{ll}T: & \text { Torque on the bolt }(\mathrm{Nm}) \\ F: & \text { Pretension on the bolt }(\mathrm{N}) \\ z: & \text { Thickness of the thin-layer element }(\mathrm{m}) \\ E: & \text { Elasticity of the tie-bolt rotor }(\mathrm{Pa}) \\ E_{\text {cont }}: & \text { Elasticity of the thin-layer element }(\mathrm{Pa}) \\ \rho: & \text { Density of the rotor }\left(\mathrm{kg} / \mathrm{m}^{3}\right) \\ F: & \text { Pretension on the bolt }(\mathrm{N}) \\ k_{n}: & \text { Normal contact stiffness of the thin-layer element } \\ v: & \text { Poisson's ratio } \\ f_{i}: & \text { Natural frequency of the } i^{\text {th }} \text { mode }(i=1-5) \\ D_{i}: & \text { Modal damping ratio of the } i^{\text {th }} \text { mode }(i=1-5) \\ f_{i}: & \text { Updated natural frequency of the } i^{\text {th }} \text { mode } \\ \widehat{D}_{i}: & \text { Updated modal damping ratio of the } i^{\text {th }} \text { mode } \\ \varepsilon_{\text {freq }}: & \text { Error of natural frequency for model updating } \\ \varepsilon_{\text {damp }}: & \text { Error of modal damping for model updating. }\end{array}$

\section{Appendix}

\section{Torque-Pretension Relationship of the Disk Spring for M16 and M20 Tie-Bolts}

According to European standard DIN 2093 [36], the authors obtain the formula of two kinds of disk springs for bolts M20 and M16. Furthermore, a quasistatic FE simulation can be used to verify the force-displacement curve, as displayed in Figure 19. The displacement is exerted on one basement, and the reaction force can be obtained from the other side. Contact is set to be frictional between the disk spring and the two additional parts.

The force-deformation curve obtained from the formula as well as FE simulations is collected in Figure 20. As can be seen, the corresponding force increases with a growing frictional coefficient. Furthermore, the FE simulation demonstrates a good agreement with the results from the formula of DIN2093 in the linear region.

Due to symmetry of the structure, the preload is applied uniformly on the bolt M16 and M20 by the torque wrench ranging from $10 \mathrm{Nm}$ to $110 \mathrm{Nm}$. A combination of 8 disk springs, i.e., 4 parallel stacked springs in series, has been used to determine the axial preloads because the linear approximation is met. The deformation of disk springs with respect to multiple bolts is measured, and the average value is obtained. Therefore, the torque-deformation curve of the disk spring can be achieved as shown in Figure 21.

The pretension of the tie-bolt $F$ corresponding to an applied torque $T$ is usually calculated via an empirical formula [22]:

$$
T=F\left(0.159 P+0.578 d_{2} \mu_{T}+0.5 D_{f} \mu_{H}\right)=\alpha F,
$$

where $P$ is the bolt pitch, $d_{2}$ is the nominal bolt diameter, and $D_{f}$ is the average of the bolt cap and shaft diameters that are summarized in Table 4. Furthermore, the torque-preload relationship of the tie-bolt can be derived by a linear curve fitting as shown in Figure 17. The coefficient derived from the empirical formula $(\alpha=0.012,0.015)$ is a bit larger than the slope of the linear curve, i.e., 0.01. The reason is probably due to a reduced frictional coefficient of the bolt head in the tie-bolt with disk spring. Therefore, the relationship between torque and preload obtained from experiment is reasonable.

\section{Data Availability}

The data used to support the findings can be obtained by contacting via lipu1215@xjtu.edu.cn.

\section{Conflicts of Interest}

On behalf of all authors, the corresponding author states that there are no conflicts of interest.

\section{Acknowledgments}

This work was supported by the National Nature Science Foundation of China (nos. 11902237 and 11872289) and the China Postdoctoral Science Foundation (no. 2018M643622).

\section{References}

[1] J. Hong, X. Chen, Y. Wang, and Y. Ma, "Optimization of dynamics of non-continuous rotor based on model of rotor stiffness," Mechanical Systems and Signal Processing, vol. 131, pp. 166-182, 2019.

[2] S. Liu, Y. Ma, D. Zhang, and J. Hong, "Studies on dynamic characteristics of the joint in the aero-engine rotor system," Mechanical Systems and Signal Processing, vol. 29, pp. 120136, 2012.

[3] K. Shaposhnikov and C. Gao, "Problems of rotordynamic modeling for built-up gas turbine rotors with central tie rod shaft," Mechanisms and Machine Science, Springer International Publishing, Cham, Switzerland, pp. 250-264, 2019.

[4] C. Meng, M. Su, and S. Wang, "An investigation on dynamic characteristics of a gas turbine rotor using an improved transfer matrix method," Journal of Engineering for Gas Turbines and Power, vol. 135, no. 12, p. 122505, 2013.

[5] M. Zhuo, L. Yang, and L. Yu, "Contact stiffness calculation and effects on rotordynamic of rod fastened rotor," in Proceedings of the ASME 2016 International Mechanical Engineering Congress and Exposition: American Society of Mechanical Engineers (ASME), Phoenix, AZ, USA, November 2016.

[6] Y. Liu, Q. Yuan, and Z. Zhou, "Contact status analysis of rodfastened rotors with hirth coupling in gas turbines," in Proceedings of the ASME Turbo Expo 2015: Turbine Technical Conference and Exposition 2015, Montreal, Quebec, Canada, June 2015.

[7] A. Rimpel and M. Leopard, "Simple contact stiffness model validation for tie bolt rotor design with butt joints and pilot fits," Journal of Engineering for Gas Turbines and Power, vol. 142, p. 011014, 2019.

[8] G. Vannini, "Rotordynamic validation of an ultra high speed multistage centrifugal compressor stacked rotor," in Proceedings of the ASME Turbo Expo 2014: Turbine Technical Conference and Exposition 2014, p. 8, Düsseldorf, Germany, June 2014.

[9] D. Süß, A. Janeba, and K. Willner, "The gaul resonator: experiments for the isolated investigation of a bolted lap joint," in The Mechanics of Jointed Structures: Recent Research and Open Challenges for Developing Predictive Models for 
Structural Dynamics, M. R. W. Brake, Ed., Springer International Publishing, Cham, Switzerland, pp. 59-72, 2018.

[10] Q. Yuan, J. Gao, and P. Li, "Nonlinear dynamics of the rodfastened jeffcott rotor," Journal of Vibration and Acoustics, vol. 136, no. 2, Article ID 021011, 2014.

[11] S. M. Sah, J. J. Thomsen, M. Brøns, A. Fidlin, and D. Tcherniak, "Estimating bolt tightness using transverse natural frequencies," Journal of Sound and Vibration, vol. 431, pp. 137-149, 2018.

[12] J. J. Meyer and D. E. Adams, "Theoretical and experimental evidence for using impact modulation to assess bolted joints," Nonlinear Dynamics, vol. 81, no. 1-2, pp. 103-117, 2015.

[13] F. Huda, I. Kajiwara, N. Hosoya, and S. Kawamura, "Bolt loosening analysis and diagnosis by non-contact laser excitation vibration tests," Mechanical Systems and Signal Processing, vol. 40, no. 2, pp. 589-604, 2013.

[14] Z. Qin, Q. Han, and F. Chu, "Bolt loosening at rotating joint interface and its influence on rotor dynamics," Engineering Failure Analysis, vol. 59, pp. 456-466, 2016.

[15] Z. Qin and F. Chu, "Numerical studies on time-varying stiffness of disk-drum type rotor with bolt loosening," Journal of Physics: Conference Series, vol. 628, p. 012076, 2015.

[16] J. Gao, Q. Yuan, P. Li, Z. Feng, H. Zhang, and Z. Lv, "Effects of bending moments and pretightening forces on the flexural stiffness of contact interfaces in rod-fastened rotors," Journal of Engineering for Gas Turbines and Power, vol. 134, no. 10, pp. 102503-102508, 2012.

[17] M.-A. Beaudoin and K. Behdinan, "Analytical lump model for the nonlinear dynamic response of bolted flanges in aeroengine casings," Mechanical Systems and Signal Processing, vol. 115, pp. 14-28, 2019.

[18] Z. Qin, Q. Han, and F. Chu, “Analytical model of bolted diskdrum joints and its application to dynamic analysis of jointed rotor," Proceedings of the Institution of Mechanical Engineers, Part C: Journal of Mechanical Engineering Science, vol. 228, no. 4, pp. 646-663, 2014.

[19] L. Wang, A. Wang, M. Jin, Q. Huang, and Y. Yin, "Nonlinear effects of induced unbalance in the rod fastening rotorbearing system considering nonlinear contact," Archive of Applied Mechanics, vol. 90, no. 5, pp. 917-943, 2020.

[20] L. Gagnon, M. Morandini, and G. L. Ghiringhelli, "A review of friction damping modeling and testing," Archive of Applied Mechanics, vol. 90, no. 1, pp. 107-126, 2020.

[21] S. Bograd, P. Reuss, A. Schmidt, L. Gaul, and M. Mayer, "Modeling the dynamics of mechanical joints," Mechanical Systems and Signal Processing, vol. 25, no. 8, pp. 2801-2826, 2011.

[22] R. Lacayo, L. Pesaresi, J. Groß et al., "Nonlinear modeling of structures with bolted joints: a comparison of two approaches based on a time-domain and frequency-domain solver," Mechanical Systems and Signal Processing, vol. 114, pp. 413438, 2019.

[23] P. Li, Q. Yuan, B. Zhao, and J. Gao, "Dynamics of a rodfastened rotor considering the bolt loosening effect," in Proceedings of the ASME Turbo Expo 2019: Turbomachinery Technical Conference and Exposition 2019, p. 9, Phoenix, AZ, USA, June 2019.

[24] W. K. Belvin, Modeling of Joints for the Dynamic Analysis of Truss Structures, National Aeronautics and Space Administration, Washington, DC, USA, 1987.

[25] Q. Yuan, R. Gao, Z. Feng, and J. Wang, "Analysis of dynamic characteristics of gas turbine rotor considering contact effects and pre-tightening force," in Proceedings of the 2008 ASME
Turbo Expo, American Society of Mechanical Engineers (ASME), Berlin, Germany, pp. 983-988, June 2008.

[26] L. Gaul and M. Mayer, "Modeling of contact interfaces in built-up structures by zero-thickness elements," in Proceedings of the IMAC-XXVI: Conference \& Exposition on Structural Dynamics, Orlando, FL, USA, February 2008.

[27] Y. C. Zhang, Z. G. Du, L. M. Shi, and S. Q. Liu, "Determination of contact stiffness of rod-fastened rotors based on modal test and finite element analysis," Journal of Engineering for Gas Turbines and Power, vol. 132, pp. 47-49, 2010.

[28] G. Zhao, Z. Xiong, X. Jin, L. Hou, and W. Gao, "Prediction of contact stiffness in bolted interface with natural frequency experiment and FE analysis," Tribology International, vol. 127, pp. 157-164, 2018.

[29] C. S. Desai, M. M. Zaman, J. G. Lightner, and H. J. Siriwardane, "Thin-layer element for interfaces and joints," International Journal for Numerical and Analytical Methods in Geomechanics, vol. 8, no. 1, pp. 19-43, 1984.

[30] R. M. Lacayo and M. S. Allen, "Updating structural models containing nonlinear Iwan joints using quasi-static modal analysis," Mechanical Systems and Signal Processing, vol. 118, pp. 133-157, 2019.

[31] F. Adel, S. Shokrollahi, M. Jamal-Omidi, and H. Ahmadian, "A model updating method for hybrid composite/aluminum bolted joints using modal test data," Journal of Sound and Vibration, vol. 396, pp. 172-185, 2017.

[32] X. Zhai, C.-W. Fei, J.-J. Wang, and X.-Y. Yao, "Parametric modeling and updating for bolted joints of aeroengine casings," Proceedings of the Institution of Mechanical Engineers, Part C: Journal of Mechanical Engineering Science, vol. 230, no. 16, pp. 2940-2951, 2016.

[33] B. Peeters, H. Van der Auweraer, P. Guillaume, and J. Leuridan, "The PolyMAX frequency-domain method: a new standard for modal parameter estimation?" Shock and Vibration, vol. 11, Article ID 523692, 15 pages, 2004.

[34] L. Gaul and A. Schmidt, "Finite element simulation and experiments on rotor damping assembled by disc shrink fits," Mechanical Systems and Signal Processing, vol. 127, pp. 412422, 2019.

[35] R. L. Fox and M. P. Kapoor, "Rates of change of eigenvalues and eigenvectors," AIAA Journal, vol. 6, no. 12, pp. 2426-2429, 1968.

[36] H. Roloff and W. Matek, "Elastische federn," Maschinenelemente: Normung, Berechnung, Gestaltung, Vieweg+Teubner Verlag, Wiesbaden, Germany, pp. 201-241, 1976. 